\title{
Effects of Pentoxifylline on the Cardiovascular Manifestations of Group B Streptococcal Sepsis in the Piglet
}

\author{
TERESA DEL MORAL, RONALD N. GOLDBERG, CLEIDE SUGUIHARA, OCTAVIO MARTINEZ, \\ WILLIAN J. FEUER, AND EDUARDO BANCALARI \\ Department of Pediatrics, Division of Neonatology, Department of Microbiology and Orthopedics, and \\ Department of Ophthalmology, Division of Biostatistics, University of Miami School of Medicine, \\ Miami, Florida 33101
}

\begin{abstract}
Pentoxifylline (PTXF) is a methylxanthine that modifies leukocyte function and inhibits cytokine release. To evaluate its effects on the cardiovascular manifestations of sepsis secondary to group B streptococci, 14 anesthetized, mechanically ventilated piglets were studied over a $240-\mathrm{min}$ period. Animals were randomly assigned to a treatment group that received a PTXF bolus $(20 \mathrm{mg} /$ $\mathrm{kg}$ ) followed by a continuous infusion of $5 \mathrm{mg} / \mathrm{kg} / \mathrm{h}$ before and during group $B$ streptococci $\left(1 \times 10^{8}\right.$ colony forming units $/ \mathrm{kg} / \mathrm{min}$ ) administration and a control group that received saline as a placebo. Comparison of the hemodynamic measurements and arterial blood gases during the first 90 min of PTXF treatment with those of the control group resulted in the following $90 \mathrm{~min}$ values: systemic arterial blood pressure was significantly higher in the PTXF group $(89 \pm 10$ versus $56 \pm 30 \mathrm{~mm} \mathrm{Hg} ; p<0.005)$ as was cardiac output $(0.18 \pm 0.04$ versus $0.10 \pm 0.07 \mathrm{~L} / \mathrm{kg} / \mathrm{min} ; p<$ 0.005). Pulmonary vascular resistance remained lower in the PTXF-treated animals $(135 \pm 117$ versus $248 \pm 119$ $\mathrm{mm} \mathrm{Hg} / \mathrm{L} / \mathrm{min} / \mathrm{kg} ; p<0.001$ ), and these animals were less acidotic as measured by $\mathrm{pH}(7.07 \pm 0.2$ versus $7.31 \pm 0.1$; $p<0.05)$ and base deficit $(-15 \pm 9$ versus $-5 \pm 2 \mathrm{mmol} /$ $\mathrm{L} ; \boldsymbol{p}<0.05$ ). Median survival time was significantly longer in the PTXF group ( 210 versus $90 \mathrm{~min} ; p<0.002$ ). These data demonstrate that PTXF can ameliorate some of the deleterious hemodynamic manifestations of group B streptococci sepsis and result in improved survival in a young animal model. (Pediatr Res 31: 596-600, 1992)
\end{abstract}

\section{Abbreviations}

$\mathrm{CO}$, cardiac output

GBS, group B streptococci

PTXF, pentoxifylline

PVR, pulmonary vascular resistance

Ppa, pulmonary artery pressure

Pra, right atrial pressure

SVR, systemic vascular resistance

Psa, systemic arterial blood pressure

During sepsis, bacteria and their products stimulate inflammatory cells, which results in the release of various mediators and cytokines such as tumor necrosis factor- $\alpha$ and IL-1. Tumor

Received April 30, 1991 ; accepted January 30, 1992

Correspondence and reprint requests: Teresa del Moral, M.D., Department of Pediatrics (R-131), University of Miami School of Medicine, P.O. Box 016960 Miami, FL 33101

Supported in part by the University of Miami Project: New Born. necrosis factor- $\alpha$ is purported to be responsible for the lethal effect of endotoxin and other bacterial products $(1,2)$. To some extent, activation of phagocytic cells and release of mediators during sepsis may be considered to be similar to a hypersensitization reaction to bacterial products. Often the resulting intense phagocytic activity can lead to nonspecific injury to surrounding tissue (3).

Traditionally, therapy for sepsis and septic shock has been aimed at eradication of bacteria and at general cardiovascular support. This approach has resulted in only modest improvement in outcome for the neonate. PTXF, a methylxanthine derivative, is an agent that may mitigate the hypersensitization response to infection. This drug diminishes lysosomal enzyme release and superoxide generation by stimulated neutrophils $(3,4)$ and decreases the production and effects of tumor necrosis factor- $\alpha$ and IL-1 (2, 5-7). Furthermore, PTXF attenuates tumor necrosis factor-endothelial cell injury in the presence of polymorphonuclear cells (8). These properties tend to lessen the reaction or overreaction of the animal to a septic challenge.

Based on the above properties, we hypothesized that the cardiovascular effects and consequently survival from bacterial challenge might be modified favorably by PTXF. The purpose of this study was to test this hypothesis in a young animal model of GBS sepsis and to evaluate various dosages of PTXF to elucidate its clinical effectiveness and potential cardiovascular side effects.

\section{MATERIALS AND METHODS}

Twenty-six Yorkshire piglets aged 7-10 d were anesthetized with pentobarbital $(30 \mathrm{mg} / \mathrm{kg}$, intraperitoneally). A tracheostomy was performed and a 5-mm endotracheal tube placed. Femoral arteries and veins were cannulated and used for measurement of Psa, blood sampling, and infusion of bacteria, fluids, and drugs. The left external jugular vein was cannulated and the catheter advanced into the right atrium for measurement of Pra and injection of ice cold saline, which was used to measured CO. A 5 French Swan-Ganz thermodilution catheter was introduced into the right external jugular vein, advanced under fluoroscopy into the left pulmonary artery, and used to measure Ppa and pulmonary wedge pressures. Heparinized normal saline $(10 \mathrm{U} /$ $\mathrm{mL}$; maximum of $300 \mathrm{U}$ delivered during the experiment) was infused continuously through the pulmonary artery catheter and an infusion of $6 \mathrm{~mL} / \mathrm{kg} / \mathrm{h}$ of $5 \%$ dextrose solution was infused through a peripheral vein. Vascular pressures were measured with pressure transducers (model P23-ID; Gould Instruments, Cleveland, $\mathrm{OH}$ ) and recorded on a multichannel recorder (model 7 polygraph; Grass Instrument Co., Quincy, MA).

The animals were ventilated with a time-cycled, pressurelimited, infant ventilator (Bourns BP 200, Riverside, CA). Arte- 
rial blood gases in the normal range were obtained by setting peak inflation pressure at $11 \pm 1 \mathrm{~cm} \mathrm{H}_{2} \mathrm{O}$, positive end-expiratory pressure at $2 \mathrm{~cm} \mathrm{H}_{2} \mathrm{O}$, and respiratory rate at 40 breaths $/ \mathrm{min}$. Animals were ventilated with room air, and settings were not altered during the study period. Animals were paralyzed with pancuronium bromide using an initial dose of $0.2 \mathrm{mg} / \mathrm{kg}$ i.v. followed by a continuous infusion of $0.4 \mathrm{mg} / \mathrm{kg} / \mathrm{h}$. Rectal temperature was continuously monitored with a thermistor probe (Yellow Springs Instrument Co., Yellow Springs, $\mathrm{OH}$ ), and skin temperature was maintained at $38.5^{\circ} \mathrm{C}$ by a servo-controlled radiant warmer.

Group B $\beta$-hemolytic streptococci, type Ia/c, isolated from an infected neonate cared for in the neonatal intensive care unit at Jackson Memorial Hospital were cultured in Todd-Hewitt broth for $18 \mathrm{~h}$ at $37^{\circ} \mathrm{C}$. The organisms were collected by centrifugation, washed twice in pyrogen-free saline, and resuspended in sterile Ringer's lactate solution with $5 \%$ dextrose at a concentration determined by OD measurements to be equivalent to $7.9 \times 10^{9}$ colony forming units $/ \mathrm{mL}$. The bacterial cell suspension was free of endotoxin as determined by a limulus amebocyte lysate test (Associate of Cape Cod, Woods Hole, MA) with a sensitivity of $>0.03$ endotoxin units $/ \mathrm{mL}$.

Bacteria were then infused through a femoral vein at a rate calculated to deliver approximately $1 \times 10^{8}$ colony forming units $/ \mathrm{kg} / \mathrm{min}$. This infusion was started $30 \mathrm{~min}$ after the PTXF or placebo infusion was begun and continued until the animal died or 240 min elapsed.

PTXF $(20 \mathrm{mg} / \mathrm{kg})$ was mixed with $10 \mathrm{~mL}$ of sterile water and given as an initial rapid infusion over 10 min followed by a continuous infusion throughout the study. To determine the dose of PTXF to be used as a continuous infusion, the following dosage regimens were tested: $20 \mathrm{mg} / \mathrm{kg} / \mathrm{h}(n=6), 10 \mathrm{mg} / \mathrm{kg} / \mathrm{h}$ $(n=2)$, and $5 \mathrm{mg} / \mathrm{kg} / \mathrm{h}(n=4)$. Because the results showed marked hypotension after 90 min of PTXF plus GBS infusion using a continuous infusion of either 10 or $20 \mathrm{mg} / \mathrm{kg} / \mathrm{h}$, but not with $5 \mathrm{mg} / \mathrm{kg} / \mathrm{h}$ (Table 1), the latter was chosen for the study.

Assays of plasma PTXF levels were performed in five animals receiving a continuous infusion of $20 \mathrm{mg} / \mathrm{kg} / \mathrm{h}$ of PTXF and in four animals receiving $5 \mathrm{mg} / \mathrm{kg} / \mathrm{h}$ at $15,45,60$, and $120 \mathrm{~min}$ after the beginning of PTXF infusion, using methods described previously by Burrows (9).

Additional animals were randomly assigned to a treatment group $(n=7)($ mean $\pm \mathrm{SD}$; weight, $3687 \pm 577 \mathrm{~g}$; age, $9 \pm 1 \mathrm{~d})$ that received PTXF as a $20-\mathrm{mg} / \mathrm{kg}$ bolus over $10 \mathrm{~min}$ followed by a continuous infusion of $5 \mathrm{mg} / \mathrm{kg} / \mathrm{h}$ throughout the remainder of the study. Seven piglets (weight, $3171 \pm 515 \mathrm{~g}$; age, $8 \pm 1 \mathrm{~d}$ ) were assigned to the control group and received $10 \mathrm{~mL}$ of normal saline over the same time period, followed by a continuous infusion of normal saline at the same rate as the continuous infusion of PTXF.

After a 60-min stabilization period, hemodynamic measurements (Psa, Ppa, pulmonary wedge pressure, $\mathrm{CO}$, and Pra) and arterial blood gases were obtained before any intervention (baseline 1). The PTXF or placebo bolus was then started, followed by a continuous infusion. Before the beginning of bacterial infusion, all measurements were repeated and this was considered baseline 2. Thirty min after the start of PTXF or placebo, GBS infusion was initiated. Hemodynamic measurements and blood gases were obtained $15 \mathrm{~min}$ after the beginning of bacterial infusion and were subsequently measured at 30 and $60 \mathrm{~min}$ and then every $30 \mathrm{~min}$ until death or until $240 \mathrm{~min}$ had elapsed. PVR, SVR, and stroke volume were calculated.

Handling and care of animals were in accordance with the guidelines of the National Institutes of Health, and this study protocol was approved by the Animal Care Committee of the University of Miami, School of Medicine.

Dependent variables in this study include Ppa, Psa, pulmonary wedge pressure, stroke volume, $\mathrm{CO}, \mathrm{pH}$, arterial $\mathrm{PO}_{2}$, arterial $\mathrm{PCO}_{2}$, base deficit, PVR, and SVR. Data are expressed as mean $\pm \mathrm{SD}$. Repeated measures analysis of covariance was used to compare the pattern of response to treatment against the control response, both over time and independent of time. Significant mortality in the control group prevented us from analyzing data after $120 \mathrm{~min}$, and, in fact, several control animals died between 90 and $120 \mathrm{~min}$. For this reason, analyses were performed using both 90 and $120 \mathrm{~min}$. In general, the two analyses supported each other, and $p$ values presented in the text are from the 90 min comparisons except in the dose-response study, in which they include values up to $120 \mathrm{~min}$. These values are HuynhFeldt corrected for correlations between the same animals at different times. Survival time was compared between groups using the Mann-Whitney $U$ test because all animals were followed either to death or to the end of the study.

\section{RESULTS}

In the preliminary study, which evaluated various continuous infusion doses of PTXF, it was noted that by $120 \mathrm{~min}$ Psa decreased approximately $38 \%$ when an infusion of either 10 or $20 \mathrm{mg}$ of PTXF $/ \mathrm{kg} / \mathrm{h}$ was used (Table 1 ). In contrast mean Psa was significantly higher in the group treated with $5 \mathrm{mg} / \mathrm{kg} / \mathrm{h}$ compared with those receiving $20 \mathrm{mg} / \mathrm{kg} / \mathrm{h}(p<0.05)$ (Table 1). Serum PTXF levels were $13080 \pm 3306,25700 \pm 7001$, and $33190 \pm 2688 \mathrm{ng} / \mathrm{mL}$ at 15,60 , and $120 \mathrm{~min}$, respectively, for animals receiving $20 \mathrm{mg} / \mathrm{kg} / \mathrm{h}$ and $17830 \pm 12700,10720 \pm$ 5618 , and $8722 \pm 3001 \mathrm{ng} / \mathrm{mL}$ for those receiving $5 \mathrm{mg} / \mathrm{kg} / \mathrm{h}$. Values at 60 and $120 \mathrm{~min}$ were significantly higher $(p<0.02$ and 0.002 , respectively) in those animals receiving the $20-\mathrm{mg} /$ $\mathrm{kg} / \mathrm{h}$ infusion. Furthermore, four out of six animals receiving an infusion of $20 \mathrm{mg}$ of PTXF/ $\mathrm{kg} / \mathrm{h}$ died within $150 \mathrm{~min}$ of starting GBS as opposed to no deaths in the group receiving $5 \mathrm{mg} / \mathrm{kg} / \mathrm{h}$ during the same time period.

As a result of these pilot findings, the main study was performed comparing control animals with a group receiving a continuous infusion of PTXF at a rate of $5 \mathrm{mg} / \mathrm{kg} / \mathrm{h}$.

Age and weight were not significantly different between treatment and control animals. Hemodynamic measurements at baseline were also comparable between groups. Furthermore, when baseline values before and after PTXF or placebo bolus were evaluated, no significant differences were noted (Table 2).

Mean Psa initially increased in both groups, but by $120 \mathrm{~min}$ it had dropped $33 \%$ from baseline in the control group. However, mean Psa in the PTXF-treated animals was maintained and was significantly higher after 60 min of GBS infusion compared with control animals (time and treatment interaction, $p<0.005$ ) (Fig. 1).

Table 1. Mean Psa (mm Hg) during different continuous infusion doses of PTXF*

\begin{tabular}{|c|c|c|c|c|c|c|c|}
\hline \multirow{2}{*}{$\begin{array}{l}\text { Continuous } \\
\text { infusion } \\
(\mathrm{mg} / \mathrm{kg} / \mathrm{h})\end{array}$} & \multicolumn{2}{|c|}{ PTXF } & & & & & \\
\hline & $\mathrm{BL}_{1}$ & $\mathrm{BL}_{2}$ & $15 \mathrm{~min}$ & $30 \mathrm{~min}$ & $60 \mathrm{~min}$ & $90 \mathrm{~min}$ & $120 \mathrm{~min}$ \\
\hline $20(n=6)$ & $79 \pm 19$ & $76 \pm 22$ & $99 \pm 18$ & $92 \pm 11$ & $87 \pm 15$ & $67 \pm 21$ & $50 \pm 30$ \\
\hline $10(n=2)$ & $86 \pm 0$ & $80 \pm 7$ & $97 \pm 7$ & $92 \pm 7$ & $94 \pm 12$ & $61 \pm 41$ & $46 \pm 13$ \\
\hline $5(n=4)$ & $89 \pm 16$ & $81 \pm 11$ & $110 \pm 12 \dagger$ & $109 \pm 15 \dagger$ & $101 \pm 12 \dagger$ & $91 \pm 133 \dagger$ & $82 \pm 16 \dagger$ \\
\hline
\end{tabular}

$* \mathrm{BL}_{1}$, baseline $1 ; \mathrm{BL}_{2}$, baseline 2 . All animals received an initial bolus of $20 \mathrm{mg} / \mathrm{kg}$ of $\mathrm{PTXF}$ between $\mathrm{BL}_{1}$ and $\mathrm{BL}_{2}$.

$\dagger p<0.05$. Statistical analysis refers to comparison between 5 and $20 \mathrm{mg} / \mathrm{kg} / \mathrm{h}$ infusion rates (repeated measures analysis of variance). 
Table 2. Hemodynamic values for control (C) and PTXF (P) groups*

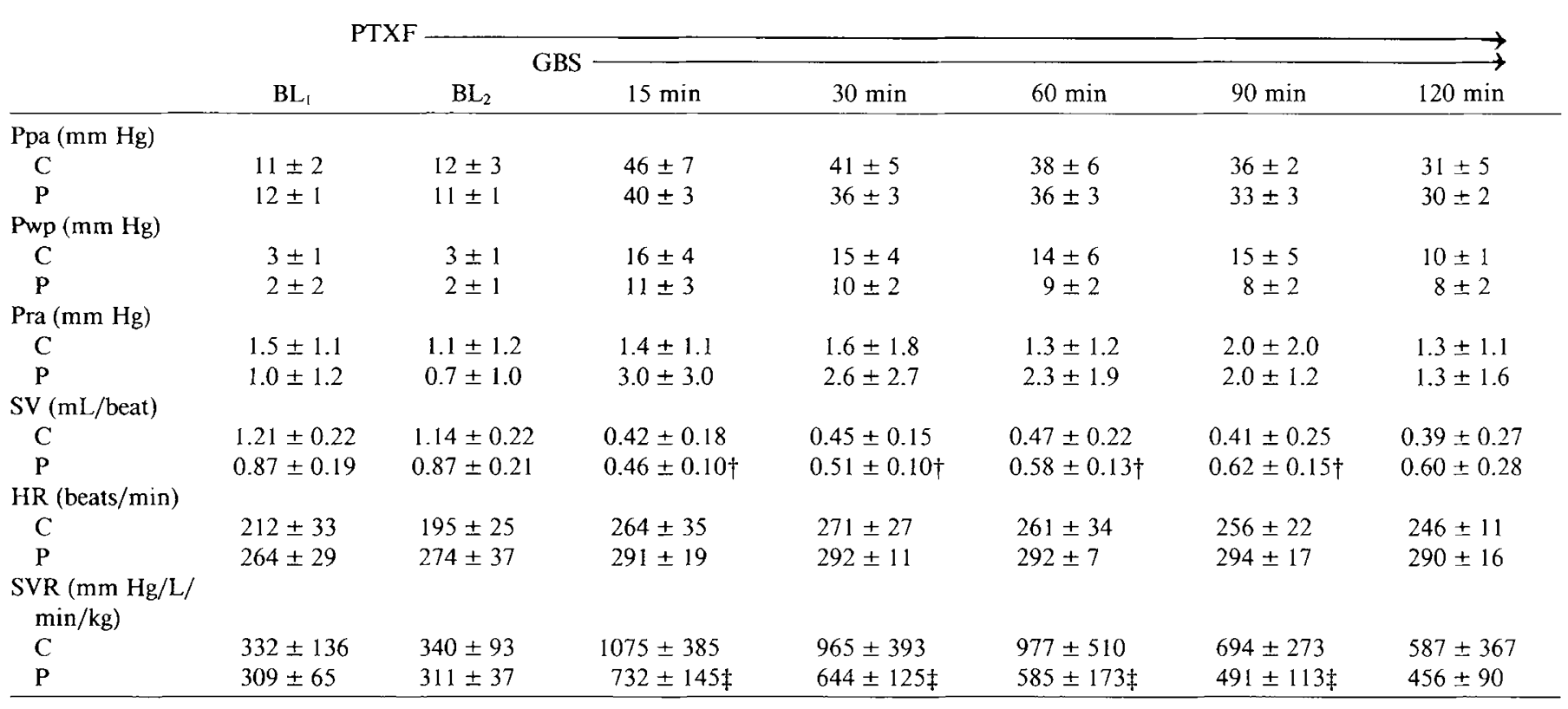

* Pwp, pulmonary wedge pressure; SV, stroke volume; and HR, heart rate. SV was increased over time after GBS infusion in the P group. SVR was lower after GBS infusion in the PTXF group independent of time. $P=$ PTXF $20 \mathrm{mg} / \mathrm{kg}+5 \mathrm{mg} / \mathrm{kg} / \mathrm{h}$.

$\dagger p<0.02$

$\ddagger p<0.05$.
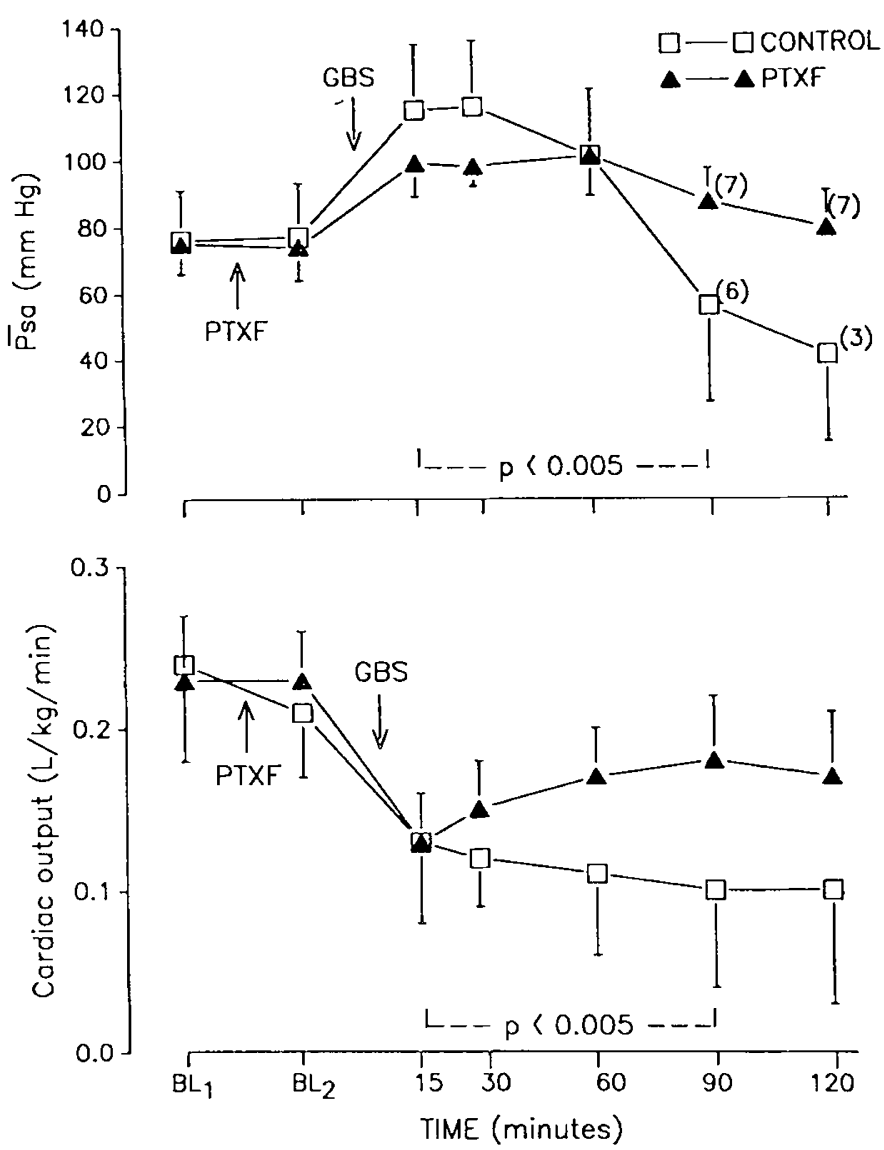

Fig. 1. Upper panel, Effect of PTXF treatment on mean Psa. Mean arterial pressure after GBS infusion was significantly higher compared with the control group $(p<0.005)$. Lower panel, $\mathrm{CO}$ was significantly lower in the control group compared with the PTXF-treated animals ( $p$ $<0.005$ ).
CO initially decreased comparably in both groups with GBS administration but was significantly higher (time and treatment interaction, $p<0.005)$ over time $(15$ to $90 \mathrm{~min}$ after bacteria infusion started) in the PTXF-treated animals (Fig. 1). The net result was a $20 \%$ decline in CO in PTXF-treated animals compared with a $65 \%$ decrease for control animals at $120 \mathrm{~min}$. Heart rate was not significantly different during the bacterial infusion; however, stroke volume continued to rise in the PTXF-treated group after it had dropped in the control group (time and treatment interaction, $p<0.02$ ) (Table 2).

Ppa and Pra were not significantly different between groups (Table 2). However, pulmonary wedge pressure showed a trend toward being higher in the control group $(p=0.057)$. After GBS infusion, PVR remained lower in the PTXF group (treatment effect, $p<0.001$ ) than in control animals (Fig. 2). Also, SVR was lower in the PTXF-treated than in the control group (treatment effect, $p<0.05$ ) (Table 2).

Arterial $\mathrm{O}_{2}$ and $\mathrm{CO}_{2}$ tension levels were also not significantly different. However, $\mathrm{pH}$ and base deficit reflected significantly less acidosis (time treatment interaction, $p<0.05$ ) in the PTXF group over the study period (Table 3 ).

At $120 \mathrm{~min}, 100 \%$ of the PTXF-treated animals were alive

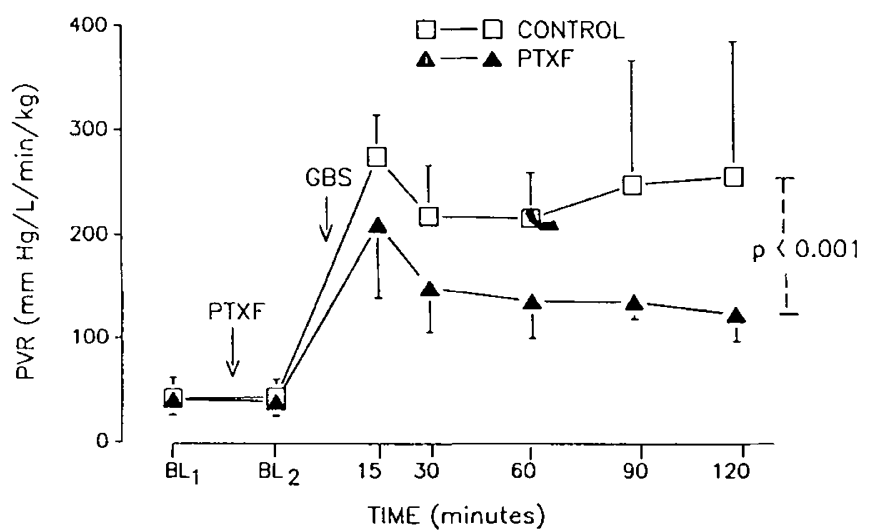

Fig. 2. PVR was significantly lower in the PTXF-treated group independent of time $(p<0.001)$. 
Table 3. Arterial blood gases and acid-base balance for control $(C)$ and PTXF (P) groups*

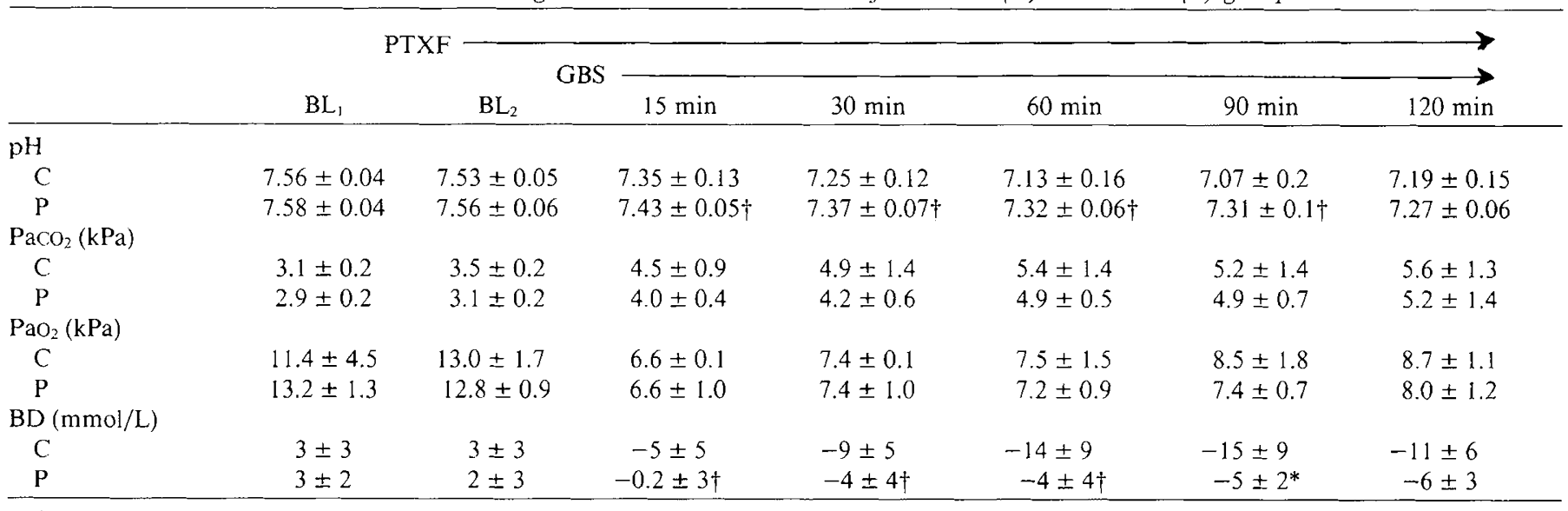

${ }^{*} \mathrm{P}=\mathrm{PTXF} 20 \mathrm{mg} / \mathrm{kg}+5 \mathrm{mg} / \mathrm{kg} / \mathrm{h}$. BL 1 , baseline 1; $\mathrm{BL}_{2}$, baseline 2; $\mathrm{PaCO}_{2}$, arterial $\mathrm{PCO}_{2} ; \mathrm{PaO}_{2}$, arterial $\mathrm{PO}_{2} ;$ and $\mathrm{BD}$, base deficit. $\dagger p<0.05$ (C vs P).

compared with $40 \%$ in the control group. The PTXF-treated animals survived significantly longer than the control animals (median 210 versus $90 \mathrm{~min})(p<0.002)$ (Fig. 3).

\section{DISCUSSION}

The results of the present study suggest that pretreatment with PTXF results in substantial protection against the hemodynamic effects of an infusion of GBS in a young animal model. Specifically, our data indicate that pretreatment with PTXF modifies the cardiovascular manifestations of sepsis, such as hypotension and diminished $\mathrm{CO}$, and improves survival in this highly lethal model of sepsis. The mechanisms by which PTXF ameliorates these hemodynamic manifestations are unclear, which is in part a reflection of the uncertainty concerning the mechanism of septic injury.

Recently, Gibson et al. (2) noted that PTXF attenuated GBSinduced tumor necrosis factor production in a septic piglet model and that its administration resulted in mild improvement in Ppa, $\mathrm{PVR}$, and arterial $\mathrm{Po}_{2}$. They also noted that animals receiving GBS plus PTXF had significantly greater systemic hypotension after $4 \mathrm{~h}$ of GBS infusion when compared with those animals receiving GBS alone. The methods and results of the present study differ in the following ways. First, Gibson et al. (2) used an infusion of $20 \mathrm{mg} / \mathrm{kg} / \mathrm{h}$. The hypotension seen in animals receiving this dose is anticipated by our preliminary dose-response study and may in part be explained by elevated PTXF

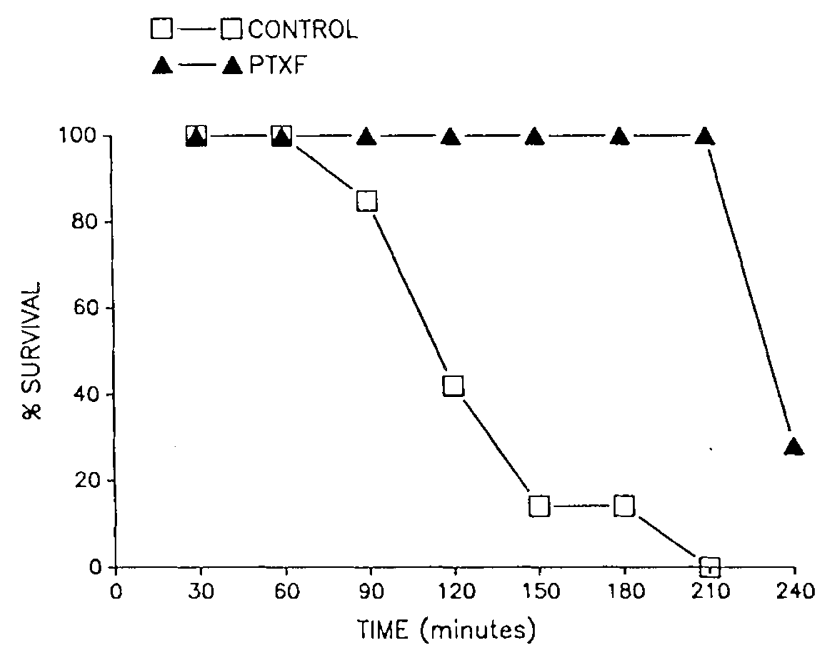

Fig. 3. Length of survival time after bacterial infusion was significantly longer in the PTXF-treated animals $(p<0.002)$ levels. Second, our model is a highly lethal one that to some extent mimics the rapid progression and severe hemodynamic instability seen in the severely ill septic neonate. As a consequence, the nature of our model and dose of PTXF used allowed detection of an overall beneficial effect of PTXF on blood pressure, CO, PVR, and length of survival.

Published animal studies suggest that a continuous infusion of a dose of $20 \mathrm{mg}$ of PTXF $/ \mathrm{kg} / \mathrm{h}$ may be beneficial and necessary during sepsis to inhibit tumor necrosis factor-induced pulmonary vasoconstriction in the septic piglet (2). However, data from the present study revealed that the use of higher continuous infusion doses of PTXF $(20 \mathrm{mg} / \mathrm{kg} / \mathrm{h})$ resulted in earlier death and significant hypotension, a finding confirmed by other studies (2, $10)$. This may be related to an exaggeration of the late sepsisinduced increase in prostacyclin (11) secondary to PTXF (2) or to a direct toxic effect of PTXF accumulation during sepsis. This is supported by our findings that PTXF levels in animals receiving $20 \mathrm{mg} / \mathrm{kg}$ were two to three times higher than those in the 5 $\mathrm{mg} / \mathrm{kg} / \mathrm{h}$ group. Hypotension or other adverse hemodynamic changes were not observed when a bolus of PTXF was given before infusing bacteria in this study. Longer infusions of PTXF are described by Gibson et al. (2) and appear to be well tolerated in the hemodynamically stable animal.

Plasma PTXF levels achieved in this model are higher than those reported in the literature (12). Reasons for this may include the following: 1) the doses of PTXF used in experimental models of sepsis have been considerably higher than those traditionally given to humans to treat intermittent claudication, and 2) the model reported in this study uses young animals, which may have different pharmacokinetic characteristics and drug metabolism than the adult (i.e. lower clearance and greater volume of distribution).

During the GBS infusion in the present study, mean Psa fell significantly in the control group, whereas that of the PTXFtreated animals remained stable. An explanation for the beneficial effects of low doses of PTXF on mean Psa during sepsis is unclear. PTXF is known to inhibit phosphodiesterase and increase intracellular concentrations of cAMP (13). Increases in cAMP secondary to adrenergic stimulation have been associated with improvement in $\mathrm{CO}(6)$, an effect that may contribute to the prevention of hypotension. Furthermore, PTXF has been shown to decrease the release of tumor necrosis factor- $\alpha$ (2), which has been associated with depression of $\mathrm{CO}$ as well as hypotension $(14,15)$. This observation is supported by the work of Lilly et al. (6), who demonstrated that PTXF-treated animals exposed to tumor necrosis factor had significantly higher mean Psa compared with controls.

In the present study, $\mathrm{CO}$ decreased approximately $20 \%$ in the PTXF-treated animals versus $65 \%$ in control animals. This was 
most likely related to increased stroke volume in the PTXF group secondary to an improvement in myocardial contractility or a lesser increase in SVR. PTXF has been shown to increase contractility in isolated dog atria (16). However, properties of PTXF such as a reductions in blood viscosity and vascular resistance may largely increase $\mathrm{CO}$ by decreasing afterload rather than by affecting myocardial contractility.

Administration of PTXF in this study was associated with an early reduction in PVR, a finding also noted by Gibson et al. (2). The PTXF-induced increase in erythrocyte deformability may improve microvascular blood flow and decrease resistance (17). Hakim also showed that PTXF may have a marked vasodilatory effect in hypoxic pulmonary hypertension (18) that can be independent of its rheologic properties (19). Whether this effect is direct or via production or liberation of mediators is not clear. PTXF administration has been reported to result in enhanced vascular wall production of prostacyclin, which may cause systemic and pulmonary vasodilatation (20). This point is supported by the work of Gibson et al. (21), who noted that the systemic hypotensive effects of high-dose PTXF may be ameliorated by cyclooxygenase blockade. However, the changes in PVR and Ppa occur before significant increases in prostacyclin and in the presence of elevated thromboxane $A_{2}$, suggesting another mechanism $(2,11)$.

Another potential benefit of PTXF in this model is the improvement in base deficit and $\mathrm{pH}$. This most likely results from better maintenance of blood flow through capillary beds (22). This decrease in resistance associated with a rise in CO and Psa might improve tissue oxygen delivery. These differences in acidbase balance were not noted by Gibson et al. (2), most likely because of differences in the lethality of the GBS infusions. Our study described a significant deterioration in acid-base status over the study period, whereas the former encountered only mild changes.

A significant finding of this work, not noted in similar models, was the improvement in length of survival of PTXF-treated animals. This finding has been reported in adult animal models of peritonitis and endotoxic shock $(5,23)$. A note of caution is warranted, however, for our own data and that of others $(2,24)$ suggest that high doses of PTXF may result in systemic arterial hypotension.

In summary, the results of the present study suggest that PTXF at the dose used in this study modifies the detrimental changes in Psa, CO, pulmony wedge pressure, PVR, and acid-base status and prolongs survival during group $\mathrm{B}$ streptococcal infusion in the piglet. Furthermore, PTXF may be beneficial in neonatal sepsis after more extensive trials with the caveat that negative hemodynamic effects are associated with increased dosage.

Acknowledgments. The authors thank Dr. W. J. Novick and Hoechst-Roussel Pharmaceuticals, Inc. for generously supplying pentoxifylline and Dr. P. J. Davis of the University of Texas for performing the pentoxifylline levels.

\section{REFERENCES}

1. Tracey KJ, Lowry SF, Cerami A 1988 Cachetin/TNF in septic shock and septic adult respiratory distress syndrome. Am Rev Respir Dis 138:1377 1379
2. Gibson RL, Redding GJ, Henderson WR, Truog WE 1991 Effect of the tumor necrosis factor inhibitor pentoxifylline on hemodynamics and gas exchange. Am Rev Respir Dis 143:598-604

3. Ward P, Johnson K, Warren J, Kurkel R 1988 Immune complexes, oxygen radicals and lung injury. In: Halliwell $B$ (ed) Oxygen Radicals and Tissue Injury. Federation of American Societies for Experimental Biology, Bethesda, MD, pp 107-114

4. Bessler H, Gilgal M. Djadettim M, Zahavi I 1986 Effect of pentoxifylline on the phagocytic activity, cAMP levels, and superoxide anion production by monocytes and polymorphonuclear cells. J Leukocyte Biol 40:747-754

5. Noel $P$, Nelson $S$, Bokulic R, Bagby $G$, Lippton $H$, Lipcono $G$, Summer W 1989 Pentoxifylline inhibits lipopolysaccharide-induced serum tumor necrosis factor and mortality. Clin Res 37:31(abstr)

6. Lilly CM, Sandhu JS, Ishizaka A. Harada H, Yonemaru M, Larrick JW, Sh T, O'Hanley TF, Raffin TA 1989 PTXF prevents tumor necrosis factorinduced lung injury. Am Rev Respir Dis 139:1361-1368

7. Sullivan GW, Carper TH, Novick W, Mandell GL 1988 Inhibition of the inflammatory action of interleukin-1 and tumor necrosis factor (alpha) on neutrophil function by pentoxifylline. Infect Immun 56:1722-1729

8. Zheng H, Crowley J, Chan JC, Hoffman H, Hatherill JR, Ishizaka A, Raffin TA 1990 Attenuation of TNF-induced endothelial cells cytotoxicity and neutrophil chemiluminescence. Am Rev Respir Dis 142:1043-1078

9. Burrows JL 1987 Determination of oxpentifylline and three metabolites in plasma by automated capillary gas chromatography using nitrogen-selective detection. J Chromatogr 423:139-146

10. Tigue D, Moss R, Hynd J, Boghossian S, Al-Saady N, Heath MF, Bennett ED 1990 Pretreatment with pentoxifylline improves the hemodynamic and histologic changes and decreases neutrophil adhesiveness in a pig fecal peritonitis model. Crit Care Med 18:184-189

11. Runkle B, Goldberg RN, Streitfeld MM, Clark MB, Buron E, Setzer ES, Bancalari E 1984 Cardiovascular changes in group B streptococcal sepsis in the piglet: response to indomethacin and the relationship to prostacyclin and thromboxane $A_{2}$. Pediatr Res 18:874-878

12. Beermann B, Ings R, Mansby J, Chamberlain J, McDonald A 1985 Kinetics of intravenous and oral pentoxifylline in healthy subjects. Clin Pharmacol Ther 37:25-28

13. Stefanovich V 1975 Concerning specificity of the influence of pentoxifylline on various cyclic AMP phosphodiesterases. Res Commun Chem Pathol Pharmacol 8:673-678

14. Osiovich H, Goldberg R, Adams JA, Offenbacher S, Kuo G, Devia C, Suguihara C, Bancalari E 1989 Cardiovascular effects of TNF (r-TNF) in piglets. Pediatr Res 25:279(abstr)

15. Truog WE, Gibson RL, Henderson WR, Redding GJ 1990 Tumor necrosis factor induced neonatal pulmonary hypertension: effects of dazmegrel pretreatment. Pediatr Res 27:466-471

16. Watanabe H, Furukana Y, Schira S 1982 Cardiovascular effects of aminophylline and pentoxifylline on intact dogs and isolated dog atria. Jpn Heart J 23:235-243

17. Chick T, Scotto P, Icenoglem M, Sikes W, Doyle P, Riedel C, Wood S, Loeppky JA 1988 Effects of pentoxifylline on pulmonary hemodynamics during acute hypoxia in anesthetized dogs. Am Rev Respir Dis 137:10991103

18. Hakim TS, Petrella J 1988 Attenuation of pulmonary and systemic vasoconstriction with pentoxifylline and aminophylline. Can J Physiol Pharmacol $66: 396-401$

19. Hakim TS 1988 Reversal of pulmonary hypoxic vasoconstriction with pentoxifylline and aminophylline in isolated lungs. Can J Physiol Pharmacol 66:146-151

20. Schroer RH 1985 Antithrombotic potential of pentoxifylline. A hemorheologically active drug. Angiology 36:387-389

21. Gibson RL, Redding GJ, Henderson WR, Truog WE 1990 Combined pentoxifylline and indomethacin pretreatment attenuates early and late features of group B streptococcal sepsis in piglets. Am Rev Respir Dis 141:688(abstr)

22. Ehrly AM 1978 The effect of pentoxifylline on flow properties of human blood. Curr Med Res Opin 5:608-613

23. Schonharting MM, Schade UF 1989 The effect of pentoxifylline in septic shock. New pharmacological aspects of an established drug. J Med Clin Exp Theor 20:97-105

24. Bjornson S, Cave C, Bjornson A 1987 Effects of pentoxifylline on survival and chemotaxis of polymorphonuclear leukocytes in a rat model of bacterial peritonitis. In: Mandell GL, Novick WJ (ed) Pentoxifylline and Leukocyte Function. Hoechst-Roussel Pharmaceuticals, Somerville, NJ, pp 138-154 